\title{
Allelic Variants of the Functional Promoter Polymorphism of the Human Serotonin Transporter Gene is Associated with Auditory Cortical Stimulus Processing
}

\author{
Jürgen Gallinat*,', Daniel Senkowski ${ }^{2}$, Catrin Wernicke ${ }^{3}$, Georg Juckel $^{4}$, Isabell Becker', Thomas Sander', \\ Michael Smolka', Ulrich Hegerl' ${ }^{4}$, Hans Rommelspacher ${ }^{3}$, Georg Winterer' and Werner M Herrmann' \\ 'Department of Psychiatry, Free University of Berlin, Berlin, Germany; ${ }^{2}$ Department of Clinical Neurobiology, Free University of Berlin, Berlin, \\ Germany; ${ }^{3}$ Max-Planck-Institute of Cognitive Neuroscience, Leipzig, Germany; ${ }^{4}$ Department of Psychiatry, Ludwig-Maximilians-University, \\ Munich, Germany
}

\begin{abstract}
The loudness dependence (LD) of the auditory-evoked NI/P2 component has been shown to be related to the central serotonergic neurotransmission. Allelic variants in the promoter region of the 5-hydroxytryptamine transporter (5-HTT) gene were shown to modulate serotonergic activity. It was hypothesized that the three genotypes (I/l, s/l, s/s) differ with respect to LD. Allelic variants of the 5 $\mathrm{HTT}$ promoter region and LD at the $\mathrm{Cz}$ electrode were determined in 185 healthy subjects prospectively. A significant association was found between LD and genotype (ANOVA: $F=4.172, p=0.017$ ). Individuals homozygous for the I allele exhibited a weaker LD compared to heterozygous subjects. The results are consistent with the reported association between 5 -HTT genotype and serotonin transport capacity in lymphoblasts, and indicate that auditory stimulus processing is associated with genetic variants of the brain serotonergic system. The LD may serve as endophenotype in human serotonin research.

Neuropsychopharmacology (2003) 28, 530-532. doi:I 0. I 038/sj.npp. 1300042
\end{abstract}

Keywords: auditory-evoked potentials; loudness dependence; serotonin transporter; promoter regions; serotonin; endophenotype

\section{INTRODUCTION}

A valid indicator of central serotonergic neurotransmission would be useful for various diagnostic and psychopharmacological purposes in psychiatry because peripheral serotonergic measures only partially reflect brain serotonergic function. Since evidence for a modulation of the loudness dependence (LD) of the auditory-evoked N1/P2 component by changes of the central serotonergic activity was reported in humans (von Knorring and Perris, 1981) and animals (Juckel et al, 1997) the LD was hypothesized to be such an indicator (Hegerl and Juckel, 1993). The LD denotes the amplitude change of auditory-evoked potentials (AEPs) in response to different stimulus intensities. A strong $L D$ is supposed to indicate a low serotonergic activity and vice versa. For example, the $\mathrm{LD}$ in behaving cats was found to decrease by application of the 5-HT1a-receptor agonist 8$\mathrm{OH}-\mathrm{DPAT}$ and to increase by the 5-HT2-receptor antagonist ketanserin (Juckel et al, 1997). Of clinical interest are observations that a strong LD in depressed patients is

*Correspondence: Dr I Gallinat, Department of Psychiatry, Free University of Berlin, Eschenallee 3, I 4050 Berlin, Germany, Tel: +49 30 844586 I0, Fax: +49 3030685 122, E-mail: juergen.gallinat@charite.de Received 9 January 2002; revised 10 July 2002; accepted 19 July 2002 Online publication: 25 July 2002 at http://www.acnp.org/citations/ Npp072502359 related to a favorable therapeutical outcome to serotonin agonistic agents (Hegerl and Juckel 1993, Gallinat et al, 2000). Furthermore, a strong LD was described in abstinent ecstasy users who are supposed to possess a diminished serotonergic activity (Tuchtenhagen et al, 2000), while patients with a serotonin syndrome during SSRI treatment were shown to have a weak LD (Hegerl et al, 1998).

However, it is unknown whether LD is modulated by genetic variants of serotonergic neurotransmission. A polymorphic site in the promoter region of the 5-HTT gene comprising a long (l) and a short (s) variant has become a focus in psychiatric research (Lesch and Mossner, 1998). The 1/1 genotype was described as being associated with higher 5-HT uptake than s/l and s/s in lymphoblasts (Lesch et al, 1996) and in nucleus raphe (Heinz et al, 2000). Owing to the pivotal role of the 5-HTT in brain 5-HT homeostasis, the SLC6A4 promoter was genotyped in 185 healthy subjects to test if genotypes differ with respect to the LD.

\section{METHODS}

\section{Subjects}

The study was approved by the ethics committee of the University-Hospital Benjamin-Franklin, Berlin. The subjects gave written informed consent. A total of 185 healthy 
unrelated participants (age $39.3 \pm 13.4$ years, 96 male), all of German origin except five subjects (Austrian, Danish, British), were recruited by newspaper advertisements. A screening was performed by telephone, and a psychiatric interview (M.I.N.I, Sheehan et al, 1998) was applied just before LD recording to evaluate the exclusion criterion: axis-I or axis-II disorders, axis-I diagnosis of first-degree relatives, psychotropic drug intake, hearing disorder (whisper test and in doubtful cases $1000-\mathrm{Hz}$ tone audiometry) and any condition that may interfere with the purpose of the study.

\section{AEP-Recording}

AEP recording (Synamps-Neuroscan ${ }^{\circledR}$ ) was performed with eyes open. Tones $(1000 \mathrm{~Hz}, 40 \mathrm{~ms}$ duration, ISI $1800-$ $2200 \mathrm{~ms})$ of five intensities $(79,87.5,96,104.5$, and $113 \mathrm{dBSPL}$ ) were presented binaurally by headphones. At least 30 artefact-free $( \pm 100 \mu \mathrm{V})$ sweeps/intensity were averaged. N1 peaks (50-150 ms) and P2 peaks (100$250 \mathrm{~ms}$ ) were determined semiautomatically at a $\mathrm{Cz}$ electrode (linked-mastoids reference). The LD was calculated as a linear regression slope with stimulus intensity as an independent variable and N1/P2 amplitude as a dependent variable (Gallinat et al, 2000). Genotyping was performed as described previously (Sander et al, 1998).

\section{RESULTS}

An ANOVA revealed significant differences of the LD between the three 5-HTT genotype groups $\left(\mathrm{F}(2,182)=4.172, p=0.017, R^{2}=0.044\right)$. Post hoc analyses yielded a significant lower LD for the $1 / 1$ as compared to the s/l genotype $(p=0.022)$, but not for $1 / 1 v s \mathrm{~s} / \mathrm{s}$ genotype $(p=0.15$, Bonferroni, Figure 1$)$. No age differences were found among $1 / 1(40.8 \pm 14.2$ years $)$, s/l (38.7 \pm 12.2 years $)$ and $\mathrm{s} / \mathrm{s} \quad(37.0 \pm 13.8$ years $)$ genotype groups $(\mathrm{F}(2,182)=1.047, p=0.353)$.

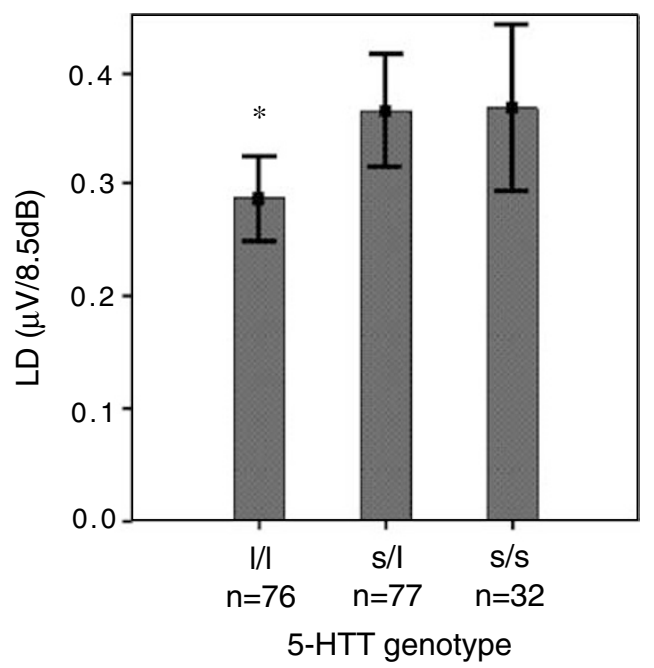

Figure I Mean values and standard error of mean of the LD for three genotypes. The $1 / /$ homozygous group has a significant weaker LD as compared to the $s / l$ group $(* p=0.022)$.

\section{DISCUSSION}

A significantly weaker LD was observed in subjects with $1 / 1$ genotype as compared to the group with s/l genotype, which may indicate a higher central serotonergic activity in subjects homozygous for the 1 allele. The 5-HTT genotype explained $4 \%$ of $\mathrm{LD}$ variance. This finding is important since it confirms and extends a recent SPECT study (Heinz et al, 2000) in suggesting that central serotonergic activity is increased in $1 / 1$ carriers. The present results are also in agreement with the observation that lymphoblasts with one or two $s$ alleles possess a lower 5HT-uptake than cells with the 1/1 genotype (Lesch et al, 1996), although in vivo measures showed conflicting results (Willeit et al, 2001).

A weak LD was originally interpreted as a consequence of a central mechanism protecting the organism from sensory overload (Buchsbaum, 1976). The later described association of LD with serotonergic neurotransmission (Hegerl and Juckel, 1993) is supposed to be based on the dense serotonergic innervation of the primary auditory cortex - the main N1/P2 generator - especially layer IV (Lewis et al, 1986). Since layer IV also receives most of the specific thalamic sensory input, brainstem serotonergic projections are in a position to modulate initial cortical signal processing (Morrison et al, 1982) and therefore the LD (Juckel et al, 1997). It was reported in behaving cats that the LD is weak during high firing rate of serotonergic neurons in dorsal raphe nucleus and vice versa (Juckel et al, 1999). It can be speculated that the weak LD of the $1 / 1$ genotype in the present data is because of a high firing rate of raphe neurons. In line with this, a higher transport capacity of the 1/1 genotype was suggested to exert a somatodendritic 5HT1a-receptor-mediated negative feedback with an overall increase of 5-HT neurotransmission (Lesch and Mossner, 1998). Such a mechanism might decrease the LD generated in the auditory cortex and may explain the present results.

Interestingly, recent animal studies indicate a primarily inhibitory effect of 5-HT even on nuclei of the ascending auditory pathway including superior olive (Fitzgerald and Sanes, 1999) and inferior colliculus (Hurley and Pollak, 1999). Furthermore, 5-HT exerts influences on neural development and probably on plasticity and function of the auditory system as well (Fitzgerald and Sanes, 1999). Therefore, it cannot be excluded that 5-HT-genotype-driven developmental alterations of subcortical structures and the ascending auditory pathway underlie the present results.

In summary, LD as a correlate of the auditory cortical stimulus processing may serve as an intermediate phenotype indicating central serotonergic activity as a function of genotype. The LD may be helpful to evaluate the functional significance of other polymorphisms of the serotonin system.

\section{REFERENCES}

Buchsbaum M (1976). Self-regulation of stimulus intensity: augmenting reducing and the average evoked response. In: Schwartz GE, Shapiro D (eds). Consciousness and self-regulation. New York: Plenum Press, pp 101-135.

Fitzgerald KK, Sanes DH (1999). Serotonergic modulation of synapses in the developing gerbil lateral superior olive. $J$ Neurophysiol 81: 2743-2752. 
Gallinat J, Bottlender R, Juckel G, Munke-Puchner A, Stotz G Kuss HJ et al (2000). The loudness dependency of the auditory evoked N1/P2-component as a predictor of the acute SSRI response in depression. Psychopharmacology (Berl) 148: 404-411.

Hegerl U, Bottlender R, Gallinat J, Kuss HJ, Ackenheil M, Moller HJ (1998). The serotonin syndrome scale: first results on validity. Eur Arch Psychiatry Clin Neurosci 248: 96-103.

Hegerl U, Juckel G (1993). Intensity dependence of auditory evoked potentials as an indicator of central serotonergic neurotransmission: a new hypothesis. Biol Psychiatry 33: 173-187.

Heinz A, Jones DW, Mazzanti C, Goldman D, Ragan P, Hommer D et al (2000). A relationship between serotonin transporter genotype and in vivo protein expression and alcohol neurotoxicity. Biol Psychiatry 47: 643-649.

Hurley LM, Pollak GD (1999). Serotonin differentially modulates responses to tones and frequency-modulated sweeps in the inferior colliculus. J Neurosci 19: 8071-8082.

Juckel G, Hegerl U, Molnar M, Csepe V, Karmos G (1999). Auditory evoked potentials reflect serotonergic neuronal activity - a study in behaving cats administered drugs acting on 5-HT1A autoreceptors in the dorsal raphe nucleus. Neuropsychopharmacology 21: 710-716.

Juckel G, Molnar M, Hegerl U, Csepe V, Karmos G (1997). Auditory-evoked potentials as indicator of brain serotonergic activity-first evidence in behaving cats. Biol Psychiatry 41: 1181-1195.

Lesch KP, Bengel D, Heils A, Sabol SZ, Greenberg BD, Petri S et al (1996). Association of anxiety-related traits with a polymorphism in the serotonin transporter gene regulatory region. Science 274: $1527-1531$.
Lesch KP, Mossner R (1998). Genetically driven variation in serotonin uptake: is there a link to affective spectrum, neurodevelopmental, and neurodegenerative disorders? Biol Psychiatry 44: 179-192.

Lewis DA, Campbell MJ, Foote SL, Morrison JH (1986). The monoaminergic innervation of primate neocortex. Hum Neurobiol 5: 181-188.

Morrison JH, Foote SL, Molliver ME, Bloom FE, Lidov HG (1982). Noradrenergic and serotonergic fibers innervate complementary layers in monkey primary visual cortex: an immunohistochemical study. Proc Natl Acad Sci USA 79: 2401-2405.

Sander T, Harms H, Dufeu P, Kuhn S, Hoehe M, Lesch KP et al (1998). Serotonin transporter gene variants in alcohol-dependent subjects with dissocial personality disorder. Biol Psychiatry 43: 908-912.

Sheehan DV, Lecrubier Y, Sheehan KH, Amorim P, Janavs J, Weiller E (1998). The Mini-International Neuropsychiatric Interview (M.I.N.I): the development and validation of a structured diagnostic psychiatric interview for DSM-IV and ICD-10. J Clin Psychiatry 59(Suppl 20): 22-33.

Tuchtenhagen F, Daumann J, Norra C, Gobbele R, Becker S, Pelz S et al (2000). High intensity dependence of auditory evoked dipole source activity indicates decreased serotonergic activity in abstinent ecstasy (MDMA) users. Neuropsychopharmacology 22: 608-617.

von Knorring L, Perris C (1981). Biochemistry of the augmentingreducing response in visual evoked potentials. Neuropsychobiology 7: 1-8.

Willeit M, Stastny J, Pirker W, Praschak-Rieder N, Neumeister A, Asenbaum $S$ et al (2001). No evidence for in vivo regulation of midbrain serotonin transporter availability by serotonin transporter promoter gene polymorphism. Biol Psychiatry 50: 8-12. 